\title{
The in-betweens
}

$\mathrm{M}$ y feelings are mixed when it comes to in-betweens. Some seem quite positive, others less so but necessary, and still others downright bad. They are bad when they seem to be cop-outs, a lack of decisiveness, or an abundance of expediency that reeks of timidity, preventing bold steps required by a situation - at least the bold steps that I think are required. Not to say that compromise in human affairs should not be pursued, at least when a good bargain is better than none at all. Fortunately, few situations offer stark choices between pure good and unadulterated evil, exceedingly rich and desperately poor, or between life and death. Not all choices, even tough choices, rise to the level of Chamberlain-like ignominious appeasements that fall somewhere in-between the extremes of peace and war. Everyday life presents us with much less fraught extremes to bracket our options.

Often, a continuous sliding scale connects extremes. Take temperature, for example. Cosmologically, it stretches from a nadir of zero degrees Kelvin, "absolute" zero, to a point rising without limit or at least as far as the fuzzy region where the concept of temperature fails. Theoretical astrophysicists can choose any point in-between in their galactic simulations, while experimentalists pick a value more constrained by the laboratory. Whether it's setting the home thermostat or reckoning the first few microseconds after the Big Bang, these choices seem devoid of personal or societal consequence. Other sliding scales feel more consequential. How much to borrow from the bank or donate to a favorite charity, how many hours of the day to devote to this or that activity, and what fraction of a city's land area to reserve for parks, are all good examples where in-betweens seem to matter more.

Sometimes, however, options are discrete with discontinuous either-or choices. The extreme discrete case offers only two choices, as in flipping a coin - heads or tails has no in-between. It's an all-ornothing outcome. If life were that uncomplicated, the whole field of decision science would not exist. However, multiple fixed points arise in many fields. Take generating energy for our electrical grid. Nuclear, hydro, wind, ocean waves, photovoltaics, natural gas, oil, and coal each stand in isolation as sources. The in-between in this case determines how, where, and in what proportion each source's now provenance-free electrical energy enters the grid. Geography, efficiency, intermittency, and cost all fuel the in-between choice, which is likely of substantial environmental and economic consequence.

Similarly, on the energy-storage side, we see clever ways to avoid landing on just one option. For example, once oil has been refined into petrol and batteries have been charged from any one of the electricity generators, the hybrid electric vehicle combines internal combustion and battery power in various flexible proportions, effectively creating a continuous scale for in-betweening the two pure alternatives.

Readers of MRS Bulletin are certainly familiar with in-betweening. Materials research is a field, not a single discipline such as physics, chemistry, metallurgy, or any of their respective specialized subdisciplines. Every advanced materials project is an in-between, amalgamating aspects of each pure discipline as needed into a useful aggregate. The materials, their character, state of development, and unrealized potential determine the proportions by which each of the pure components contributes (i.e., the precise locus of the in-between). Unlike a soup of fully dissolved and thus indistinguishable ingredients, except perhaps to trained and experienced connoisseurs' taste buds, the materials project is more like a salad of readily identifiable, individually consumable, and appreciated vegetables. Which veggie one assigns to which discipline is purely a matter of personal taste.

Many in-betweens are not so quantitative. Choices are often bracketed by adjectival ${ }^{*}$ concepts difficult to measure and quantify, such as a strong-or-weak personality, hard-or-soft to the touch, near-or-far as the crow flies, feeling ill or well, good-orbad behavior, politically right or left, ethically right or wrong, and simple-or-complex ideas. Each of these requires choosing a qualitative in-between based on human factors, alien to a scientist's reliance on measurements and yardsticks. Here, a perceptual scale is the rule. And here, most of all, the in-between, as a topic in its own right, is less practical and more philosophical and psychological. The making of in-between choices such as these relies on the maker's philosophy and psychology. But, seriously thinking about (and, as is nearly completed here, writing about) the varied nature of in-betweens is a philosophical excursion and perhaps a revealing psychological deviation from the norm deserving of closer examination and undoubtedly extensive treatment.

\section{E.N. Kaufmann}

\footnotetext{
* When dealing with adjectival options, we could extend our argument to comparative and superlative notions, for example, from good to better and best and from bad to worse and worst, but then we'd be faced with a common authors' in-between choice of longer or shorter.
} 